\title{
New Principles in Design and Technology of Multi-junction Solar Energy Converters
}

\author{
Chávez-Urbiola Iker, Vorobiev Yuri, and Ramirez-Bon Rafael
}

\begin{abstract}
The multi-junction solar energy converters can be made cheap and efficient, if some new principles are applied for their design. We propose to make each p-n junction of the converter electrically independent with its own contacts. It eliminates obligatory series connection of the junctions, and allows using wide variety of electrical schemes, of " $p$ " and " $n$ " layers sequence, as well as of materials used. In particular, cheaper II-VI semiconductors can be used instead of III-V ones, with essentially simpler and cheaper technologies, such as Chemical Bath Deposition (CBD), Chemical Vapor Deposition (CVD) and their combination. Several structures were created to illustrate the principles stated, and the results of their characterization are presented.
\end{abstract}

Index Terms-Multi-junction solar cells, variable electrical connections, II-VI semiconductors, two-stage CBD-CVD technique, photo-chemical bath deposition.

\section{INTRODUCTION}

It is well known that relatively low efficiency of conventional solar cells (around 15\%) is a consequence of a wide solar spectrum, so that several semiconductors with different band gaps are necessary to utilize the major part of the spectrum. This is realized in multi-layers (multi junction, or tandem) solar energy converters, see [1]-[4], that have efficiency of 30-40\%, with a recent record of $44.7 \%$ [4]. It must be noted that tandem construction is a widely accepted way of design of different efficient solar energy converters, like thin film Si-based cells [5] or polymer ones [6].

In tandem devices, the individual $p-n$ junctions are connected in series; therefore the less efficient junction determines the total photocurrent. To eliminate this drawback, we suggested [7], [8] that individual junctions can be separated electrically, which immediately gives additional degrees of freedom in device design, in optimization of the connections, including the different sequence of " $p$ " and " $n$ " layers, which can be prepared from the larger variety of materials. Finally, it gives a possibility to construct efficient and economic solar energy converters. In particular, instead of III-V materials and MBE technology normally used for production of tandem devices, the cheaper II-VI materials with simpler and less energy consuming CBD-CVD (Chemical Bath Deposition - Chemical Vapor Deposition) technologies can be used for construction of converters in accordance with our suggestions. Here we describe the new

Manuscript received February 28, 2015; revised July 8, 2015.

Chávez-Urbiola Iker, Vorobiev Yuri, and Ramirez-Bon Rafael are with CINVESTAV-IPN, Unidad Querétaro, 2000 Libramiento Norponiente, Fracc. Real de Juriquilla, Querétaro 76230, Mexico (e-mail: ichavez@qro.cinvestav.mx, rrbon@qro.cinvestav.mx). system design, and give an example of application of the techniques mentioned, together with some preliminary results.

\section{DESIGN OF MULTI-JUNCTION CONVERTERS WITH VARIABLE SEQUENCE OF $P-N$ LAYERS}

We suggest that each semiconductor $p$ - $n$ junction in the converter has electric contacts at both ends, and in case of 2 -junction device, an insulating layer is introduced between the two materials (Fig. 1 left - scheme of energy bands; Fig. 2 - device construction). No tunnel junction exists here. These two separated electrically cells can be connected in series, like it is in traditional tandem. However, if several converters of this kind are working, there are other possibilities of parallel/series connection, so that voltage and current of the whole battery will be optimized (see [7] for some examples).
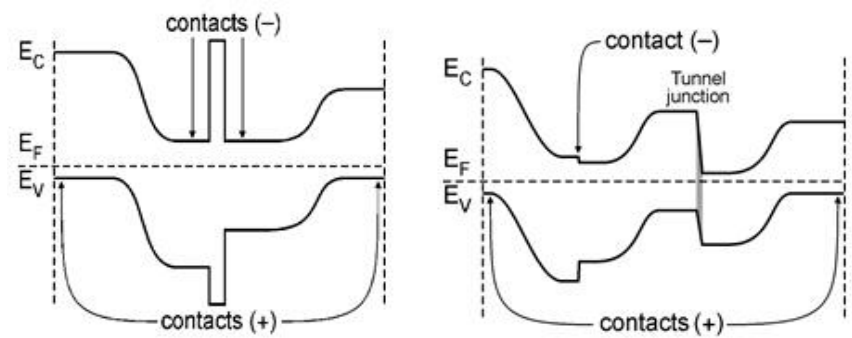

Fig. 1. Energy band diagrams of multi-junction converters with 2 (left) and 3 (right) semiconductor $p-n$-junctions.

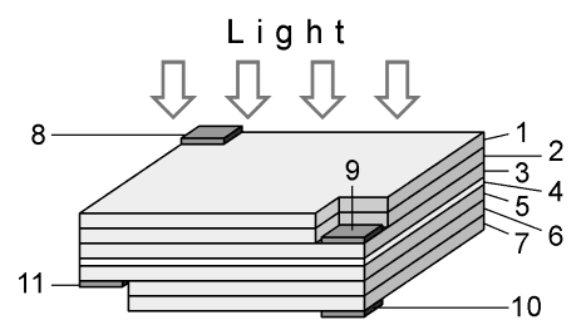

Fig. 2. Possible construction of a 2-junction converter. 1: $p$-layer of cell1; 2 : $i$-layer of it; 3: $n$-layer; 4: insulating layer; $5: n$-part of cell 2; 6: $i$-part; 7: p-layer of cell 2; 8-11: contacts.

In 3-junction device, there is a possibility to avoid the insulating layer (Fig. 1 right), with only one tunnel junction instead of 2 in traditional tandem. In this last case, the cell made of material with the largest band gap should be connected in parallel with tandem of the two other cells with smaller gap, providing that this tandem produce approximately the same voltage as the first cell. This separation of junctions allows much larger variety of materials to be used, thus giving a possibility to reduce the device cost. 
Besides the materials' cost, that of technology is essential for the total cost estimation. Many of II-VI compounds can be elaborated with CBD and CVD techniques that do not demand complicated equipment and can be realized at relatively low temperatures, with small energy consumption.

Below we describe the experimental procedures and some preliminary results. Our goal was a converter made of 3 semiconductor materials, for example, with central layer of $\mathrm{Si}$, and the two adjacent of PbTe and CdTe (CdSe), with the sequence of gaps as approximately $1.5(1.7) \mathrm{eV}, 1.1 \mathrm{eV}$ and $0,4 \mathrm{eV}$, that looks appropriate to cover all the solar spectrum. Now we present the results for $\mathrm{Si}-\mathrm{PbTe}$ diode that makes an essential part of the whole device.

\section{TECHNIQUES OF FORMATION OF SEMICONDUCTOR LAYERS}

Previously [9] we reported a $\mathrm{CdS} / \mathrm{PbS}$ solar cell made as a whole by CBD technique, with quantum efficiency of $25 \%$. In the present work, we combine two cheap low temperature deposition techniques: chemical bath deposition (CBD), which easily provides good adherence to the substrate, with chemical vapor deposition (CVD), which normally gives a large grain size and therefore high lifetime of charge carriers, usually with a high deposition rate. Based on this scheme, we reported the setup of a CVD system with a single chalcogen source to obtain cadmium or lead chalcogenides by conversion of cadmium or lead oxides/hydroxides previously deposited by $\mathrm{CBD}$. Conversion to chalcogenide films is attained by thermal ion exchange exposing the precursor metal oxide film to the chalcogen gas flux at high temperature (for the details, see [10]). We applied it to the deposition of $\mathrm{PbTe}$ films from a lead based compound plumbonacrite $\left(\mathrm{Pb}_{10}\left(\mathrm{CO}_{3}\right)_{6} \mathrm{O}(\mathrm{OH})_{6}\right)$ deposited at first stage by $\mathrm{CBD}$ under UV illumination (actually, it is Photo Chemical Bath Deposition, or PCBD). At the second stage, Te hot gas was used as the chalcogen source in CVD reactor. In a similar way, CdSe films were obtained by conversion of CBD_made substrates of cadmium oxide/hydroxide, with a Se chalcogen source [11]. Using the $n$-Si substrate covered with plumbonacrite by CBD, in a CVD reactor with Te source we obtained $n$-Si- $p$-PbTe structures, with PbTe layer thickness of around $1 \mu \mathrm{m}$.

The plumbonacrite film was made in a solution prepared in a $160 \mathrm{ml}$ flat beaker by the sequential addition of $0.2 \mathrm{M}$ of $\left(\mathrm{CH}_{3} \mathrm{COO}\right)_{2} \mathrm{~Pb} \cdot 3 \mathrm{H}_{2} \mathrm{O}$, (40 $\mathrm{ml}$ of lead acetate, trihydrate), $0.4 \mathrm{M}$ of $\mathrm{C}_{6} \mathrm{H}_{5} \mathrm{Na}_{3} \mathrm{O}_{7} \cdot 2 \mathrm{H}_{2} \mathrm{O}$ (40ml of sodium citrate, dihydrate), $0.5 \mathrm{M}$ of $\mathrm{KOH}$ (potassium hydroxide). The solution was added with deionized water to complete a total volume of $160 \mathrm{ml}$. Then the solution was placed under UV radiation with a UV lamp (364 nm main web radiation, $22 \mathrm{~W}$, see Fig. 4) at room temperature to realize a PCBD process; a white dense thin film can be seen after 5 hours. Without illumination, the deposition time necessary is almost 20 times larger. The dissociation of lead acetate gives the metal ions with the action of the complexing agent, also provides the basis for the formation of ions $\mathrm{CO}_{3}{ }^{2}-$, as well as the $\mathrm{KOH}$ provides $\mathrm{OH}^{-}$, $\mathrm{O}^{2+}$ and $\mathrm{K}^{-}$ions which are employed in the main formation reaction. The formulation used in this work is easier to prepare than one described in [12], due to the smaller amount of components; the actual process is faster due to the use of UV light.

The plumbonacrite film was placed in quartz chamber above of Knudsen pipe with tellurium powder ( $99.9 \%$ purity) in a nitrogen atmosphere at $500^{\circ} \mathrm{C}$, all this is sustained by a defined time until plumbonacrite transforms to $\mathrm{PbTe}$.

The PCBD technique was described earlier [13], [14], and used for deposition of semiconductors like $\mathrm{CdS}$ and $\mathrm{ZnS}$. In these previous papers, the deposition process was not possible without UV illumination; in our case, the deposition without illumination is possible, but with much slower rate. We believe that UV light acts as important factor in liberation of ions necessary for the deposition reaction, thus greatly accelerating it. The similar effect of UV radiation was observed in chemical bath deposition of some other semiconductors, $\mathrm{PbS}$ for example.

\section{RESULTS AND DISCUSSION}

The X-ray diffraction measurements (Fig. 3) confirmed that $\mathrm{PbTe}$ layers were formed on $\mathrm{Si}$ substrates, with complete conversion of plumbonacrite to lead telluride during $40 \mathrm{~min}$ of exposure to Te gas flow, the necessary time to transform the precursor material depends on the film thickness (for higher thickness it requires a higher time under the tellurium hot gas).

The PbTe film shows an average crystal size of $29 \mathrm{~nm}$ (found using the program WinJade with constant FWHM). Lattice constant " $a$ " was calculated according to Bragg's Law, interplanar spacing equation and using the principal plane (200), we obtain $a=\lambda / \sin \theta$, where $\lambda$ is the wavelength of the $\mathrm{X}$-ray beam $\left(\mathrm{Cu}, \lambda=1.54056 \times 10^{-10} \mathrm{~m}\right)$ and $\theta$ is the diffraction angle $\left(2 \theta=27.64^{\circ}\right.$ for $\left.(200)\right)$. Lattice parameter " $a$ " $=6.44 \AA$ that is in concordance with its power diffraction file (PDF $38-1435$ " $a "=6.45 \AA)$; The labels in each peak correspond to the crystalline planes $(h, k, l)$. The silicon planes do not appear due to the large thickness of the film.

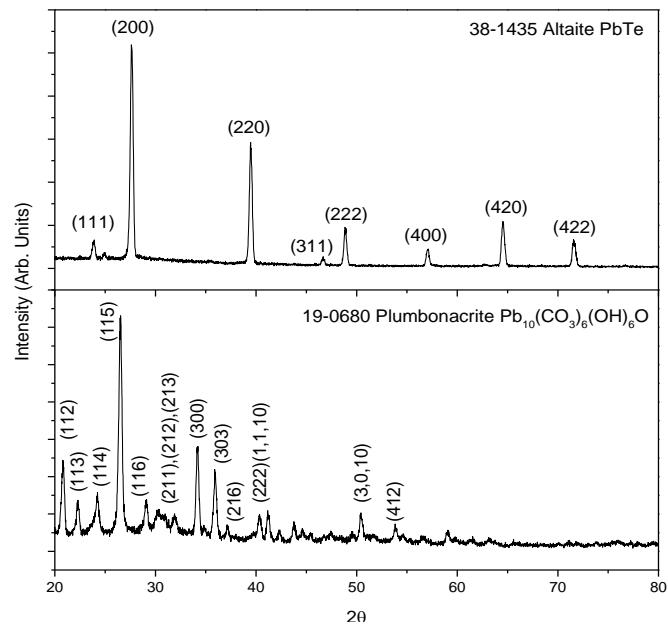

Fig. 3. X-ray diffraction pattern of lead telluride film and plumbonacrite film.

The optical properties of PbTe films were studied by diffuse reflection measurements, using the Kubelka-Munk procedure to find absorption coefficient. The derivative of the 
absorption spectrum obtained is presented in Fig. 5. Peak at $0.31-0.35 \mathrm{eV}$ corresponds to the material's absorption edge.

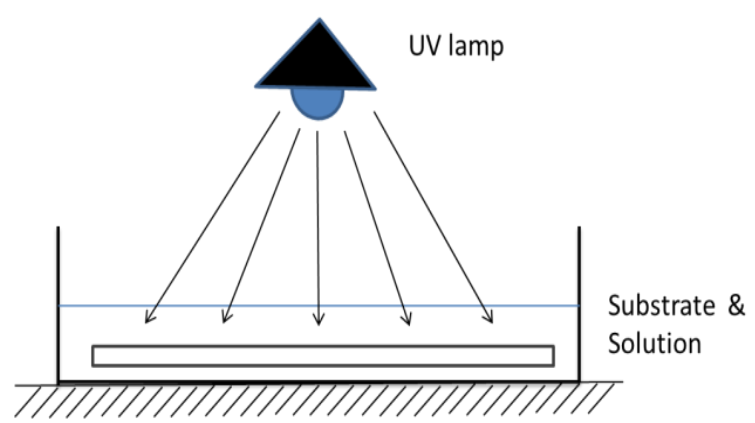

Fig. 4. Photochemical bath deposition scheme.

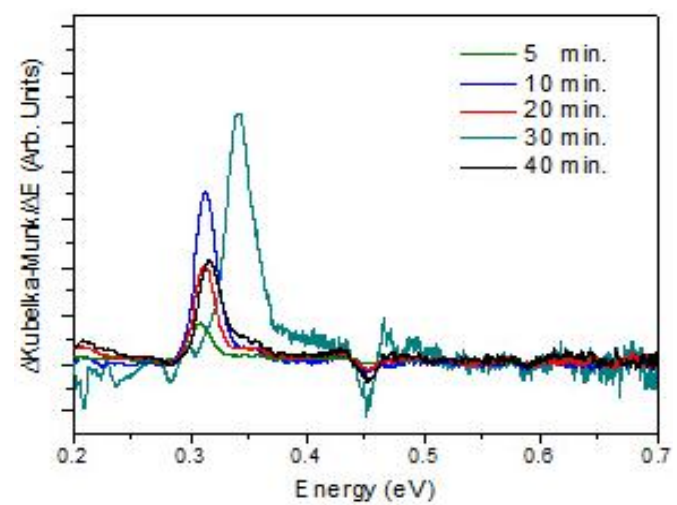

Fig. 5. Derivative of the spectra of absorption coefficient of PbTe layers.
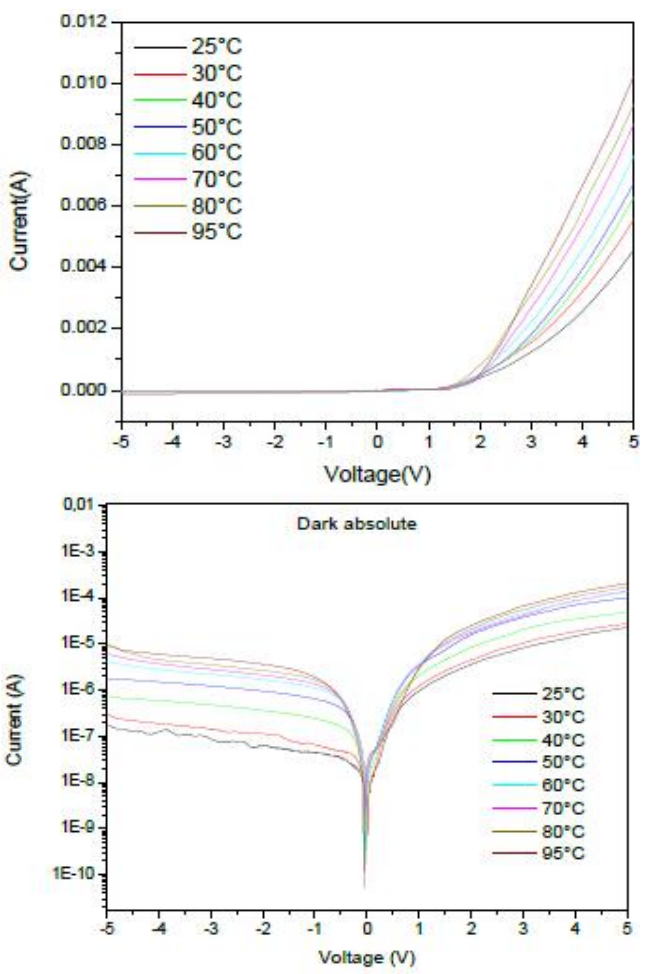

Fig. 6. Current-voltage characteristics of the diode CVD- made during 40 min (details in the text).

Fig. 6 shows the current-voltage characteristics of $n$-Si- $p$-PbTe diode obtained, at different temperatures (upper part in lineal scale, lower in logarithmic one). It is seen that both branches grow with an increase of temperature; the variation of reverse current follows exponential law, in agreement with theory. The activation energy of this dependence is $0.33 \mathrm{eV}$, so it exactly corresponds to PbTe band gap.

The I-V characteristics have clearly rectifying character, with ratio of direct to reverse current at $5 \mathrm{~V}$ around 300 at $25^{\circ} \mathrm{C}$, decreasing to 50 at $95^{\circ} \mathrm{C}$. Thus, the structure made has quite satisfactory diode parameters. The lower part of Fig. 6 presents detailed information about direct and reverse parts of diode's characteristics.

The Fig. 7 shows that illumination of the diode produces photocurrent, so that structure is really acting as solar cell, with a poor fill factor (around 20\%) leaving large space for device perfection. Device scheme is given inside the figure. Black line corresponds to the darkness, and the red one to the cell illuminated by Solar Simulator (room temperature). The parameters are given at the table nearby; it could be seen that the cell efficiency is $0.074 \%$.

Using similar CBD-CVD technique, we succeeded in production of many other useful for solar applications semiconductors, such as $\mathrm{CdSe}, \mathrm{CdTe}, \mathrm{PbS}, \mathrm{PbSe}$ (see [10] for some details). The design of multi junction solar cells using these materials is our next goal.
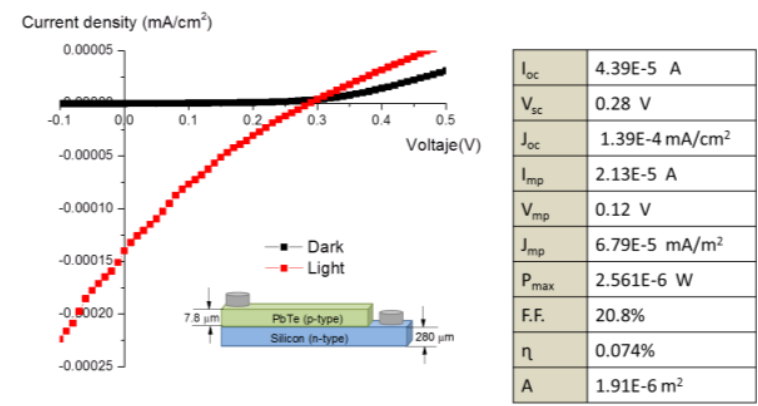

Fig. 7. I-V characteristics of Si-PbTe diode, and its parameters. The black line is obtained in the darkness, red one - with illumination.

\section{SUMMARY}

We claim that in construction of multi junction solar energy converters, the choice of materials and technologies can be greatly enlarged, if the individual semiconductor diodes are electrically separated, each one having own contacts. In this case, the converters' parts made of materials with different band gaps can be connected in optimal way, to gain maximum current and voltage. The use of II-VI materials, like $\mathrm{CdS}$, $\mathrm{CdSe}, \mathrm{CdTe}, \mathrm{PbTe}$ as well as CBD-CVD technologies can essentially reduce the device cost, preserving high conversion efficiency. The first experiments performed prove the feasibility of this approach and its great potential in devices' improvements.

\section{REFERENCES}

[1] A. Luque and S. Hegedus, Handbook of Photovoltaic Science and Engineering, Wiley, 2005.

[2] H. Cotal, C. Fetzer, J. Boisvert et al., "IIII-V multijunction solar cells for concentrating photovoltaics," Review Energy and Environmental Science, vol. 2, pp. 174-192, 2009.

[3] A. Hoffmann, U. W. Paetzold, C. Zhang et al., "Advancing tandem solar cells by spectrally selective multilayer intermediate reflectors," Optics Express, vol. 22, pp. 1270-1277, 2014.

[4] Energie durch Sonne. [Online]. Available: http://www.ise.fraunhofer.de

[5] O. Isabella, A. Hendrikus et al., "Thin-film silicon-based quadruple junction solar cells approaching $20 \%$ conversion efficiency original research article," Sol. Energy Mat. Solar Cells, vol. 129, pp. 82-89, 2014. 
[6] W. Li, A. Furlan, K. H. Hendriks et al., "Molecular materials and nanosystems, Eindhoven," The Neitherland. J. Am. Chem. Soc., vol. 135, pp. 5529-5532, 2013

[7] Y. Vorobiev, J. González-Hernández, H. Esparza-Ponce, and P. Gorley, Mexican Patent No. 274256, 2010.

[8] Y. Vorobiev, J. González-Hernández, H. Esparza-Ponce, and P. Vorobiev, Mexican Patent No. 312841, 2013.

[9] J. H. Borja, Y. V. Vorobiev, and R. R. Bon, "Thin film solar cells of $\mathrm{CdS} / \mathrm{PbS}$ chemically deposited by an ammonia-free process," Sol. En. Mater. Solar Cells, vol. 95, pp. 1882-1888, 2011.

[10] I. R. Chávez-Urbiola, J. A. Bernal Martínez, J. Hernandez Borja, C. E. P. Garcia, R. B. Ramírez, and Y. V. Vorobiev, "Combined CBD-CVD technique for preparation of II-VI semiconductor films for solar cells," Energy Procedia, vol. 57, pp. 24-31, 2014.

[11] I. R. Chávez-Urbiola, E. A. Chávez-Urbiola, R. Ochoa-Landín, S. J. Castillo, Y. V. Vorobiev, and R. Ramírez-Bon, "Cadmium selenide film through ammonia free thermal substitution reaction on cadmium oxide hydroxide films by chemical vapor deposition," Materials Letters, vol. 116, pp. 254-257, 2013.

[12] S. J. Castillo, "Synthetic plumbonacrite thin films grown by chemical bath deposition technique," Chalcogenide Letters, vol. 10, pp. 11-17, 2013.

[13] F. Goto, M. Ichimura, and E. Arai, "A new technique of compound semiconductor deposition from aqueous solution by photochemical reactions," Jap. J. Appl. Phys., vol. 36, pp. 11-12, 1997.

[14] M. Ichimura, F. Goto, Y. Ono, and E. Arai, "Deposition of CdS and $\mathrm{ZnS}$ from aqueous solutions by a new photochemical technique," $J$. Cryst. Growth, vol. 198-199, pp. 308-312, 1999.

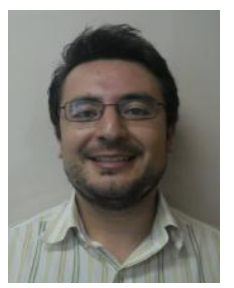

Iker Rodrigo Chávez-Urbiola was born on August 28, 1987 in Temascalcingo city, state of Mexico, Mexico. In 2010 he obtained a bachelor degree in mechanical engineering from Instituto Tecnologico de Querétaro. In 2012 he obtained a master degree in materials science from Cinvestav-Qro in the field of semiconductors processing by chemical vapor deposition and the development of the equipment. In the same year he joined the Ph.D. program in materials science at Cinvestav-Qro in the field of semiconductors processing and its applications.

His current position is a Ph.D. student at Cinvestav-Qro, in Queretaro city, Mexico where he works in his Ph.D. thesis "Research of semiconductors films by chemical vapor deposition for solar cells applications."

During his Ph.D. studies he has published some articles: 1). I. R. Chávez-Urbiola et al., "Cadmium selenide film through ammonia free thermal substitution reaction on cadmium oxide hydroxide films by chemical vapor deposition," Materials Letters, vol. 116, pp. 254-257, 2014 2). I. R. Chávez-Urbiola et al., "Combined CBD-CVD technique for preparation of II-VI semiconductor films for solar cells," Energy Procedia, vol. 57, pp. 24-31, 2014.

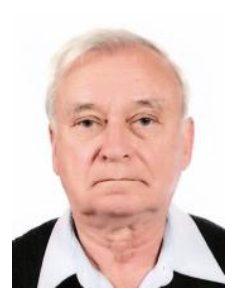

Yuri V. Vorobiev was born in Kiev, Ukraine, in 1937. He obtained his master degree in radio physics from Kiev State University, Kiev, Ukraine, in 1959, and his $\mathrm{PhD}$ degree in physics and mathematics from Kiev State University in 1966, also received his $\mathrm{PhD}$ degree in physics of semiconductors and dielectrics from the Institute of Semiconductor Physics of Ukrainian Academy of Science in 1984.

In 1986 he became a full professor of National Polytechnic Institute NTUU KPI of Kiev. Since 1996 he is a professor of CINVESTAV-IPN, Unidad Queretaro, Mexico. Authored over 170 publications, 10 patents, 4 textbooks, and supervised 36 master and $10 \mathrm{PhD}$ theses. The area of his scientific interests includes optoelectronics, semiconductor physics, solar energy conversion.

Prof. Vorobiev is a member of Ukrainian Engineering Academy and Academy of Sciences of High School of Russia. In 2005 he obtained the Award of Premio Nacional de CONAE, Mexico, for the best project in Renewable Energy Sources.

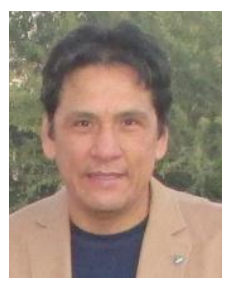

Rafael Ranirez Bon received his B.Sc. and M.Sc degrees in physics from Universidad de Sonora, and his Ph.D. degree in physics from the Physics Department at Cinvestav del IPN, Mexico. He was a research professor of physics at the Physics Research Department at Universidad de Sonora. Since 1988 he has been a research professor of materials science and engineering, Centro de Investigación y Estudios Avanzados del Instituto Politécnico Nacional, Unidad-Querétaro, at Querétaro, México. He has published more than 120 peer-reviewed papers and supervised $31 \mathrm{M} . \mathrm{Sc}$. and $20 \mathrm{Ph} . \mathrm{D}$. theses. His research interest areas are synthesis and study of optical, electrical and structural properties of semiconductor, metallic and ceramic coatings prepared by different deposition techniques. fabrication and characterization of semiconductor electronic devices including solar cells and thin film transistors. 